Citation: Guerrero-Bote, V.P., Moed, H.F., \& Moya-Anegon, F. (2021). New indicators of the technological impact of scientific production. Journal of Data and Information Science, 6(4), 36-61. https://doi. org/10.2478/jdis-20210028

Received: Mar. 5, 2021 Revised: May 6, 2021 Accepted: Jun. 3, 2021

\title{
New Indicators of the Technological Impact of Scientific Production
}

\author{
Vicente P. Guerrero-Bote ${ }^{1 \dagger}$, Henk F. Moed ${ }^{2}$, Félix Moya-Anegón ${ }^{3}$ \\ ${ }^{1}$ SCImago Group, Dept. Information and Communication, University of Extremadura, \\ Badajoz, Spain \\ ${ }^{2}$ Sapienza University of Rome, Italy \\ ${ }^{3}$ SCImago Group, Madrid, Spain
}

\begin{abstract}
Purpose: Building upon pioneering work by Francis Narin and others, a new methodological approach to assessing the technological impact of scientific research is presented.

Design/methodology/approach: It is based on the analysis of citations made in patent families included in the PATSTAT database that is to scientific papers indexed in Scopus.

Findings: An advanced citation matching procedure is applied to the data in order to construct two indicators of technological impact: on the citing (patent) side, the country/region in which protection is sought and a patent family's propensity to cite scientific papers are taken into account, and on the cited (paper) side, a relative citation rate is defined for patent citations to papers that is similar to the scientific paper-to-paper citation rate in classical bibliometrics.
\end{abstract}

Research limitations: The results are limited by the available data, in our case Scopus and PATSTAT, and especially by the lack of standardization of references in patents. This required a matching procedure that is neither trivial nor exact.

Practical implications: Results at the country/region, document type, and publication age levels are presented. The country/region-level results in particular reveal features that have remained hidden in analyses of straight counts. Especially notable is that the rankings of some Asian countries/regions move upwards when the proposed normalized indicator of technological impact is applied as against the case with straight counts of patent citations to those countries/regions' published papers.

Originality/value: In our opinion, the level of sophistication of the indicators proposed in the current paper is unparalleled in the scientific literature, and provides a solid basis for the assessment of the technological impact of scientific research in countries/regions and institutions.

Keywords Technological Impact; Patents; Scientometric; PATSTAT; Scopus

JDIS

Journal of Data and Information Science

\footnotetext{
Corresponding author: Vicente P. Guerrero-Bote (E-mail: guerrero@unex.es).
} 


\section{Introduction}

One of the most important topics in quantitative science and technology studies is the relationship between the two fields. Citation analysis is a key to gaining insight into this relationship. Citations in scientific papers to other scientific papers have long been used to assess the contribution made by individual scholars and research institutions to scientific progress, as well as to analyse the cognitive structure of science and the collaboration and flows of knowledge among scientific workers (Price, 1963). Citations made in patents to the scientific literature may similarly be used to study the influence of scientific and scholarly work on technological development. Pioneering work on patent citation analysis was conducted by Francis Narin and co-workers, who started exploring the use of patent citations to measure technological impact in the 1980s (Narin \& Olivastro, 1992; Narin, Hamilton, \& Olivastro, 1997). This is the perspective taken in the present communication. Just as a citation from the scientific literature is used to determine the scientific impact of a published scientific article, a citation from a patent can be used to determine an article's technological impact. The relationship between scientific citation and patent citation is an ongoing subject of study (Ahmadpoor \& Jones, 2017; Poege et al., 2019; Veugelers \& Wang, 2019), although some concerns have been raised about its real relevance (Bryan, Ozcan, \& Sampat, 2020; Callaert, Pellens, \& Van Looy, 2014). Nevertheless, patent analysis to construct science and technology indicators has become an active and complex discipline in its own right. Comprehensive overviews of the main methodological issues involved are given in Hinze and Schmoch (2004), Van Raan (2017), and more recently in Schmoch and Kahn (2019) and Veugelers and Wang (2019).

Technological research and development come at important costs. For this reason, when the development of a product has been completed successfully, it needs to be patented to obtain the protection that can allow its economic exploitation. A patent is a document describing a product, with the pertinent bibliography and citations to other patents and other documents. One part of the bibliography is provided by the authors and another part by the patent office's examiners. The evaluation procedure varies significantly from one national patent office to another, and consequently so may the bibliography, both the part required from the authors and the part incorporated by the examiners.

A patent family can be defined as a set of patents filed in various countries to protect a single invention. The protection in the country in which the first application is made - the priority country - is then extended to other countries. In other words, a patent family relates to the same invention disclosed by one or more common inventors and patented in more than one country. A first major problem in patent

Journal of Data and Information Science

http://www.jdis.org https://www.degruyter:com/view/j/jdis 


\section{Research Paper}

citation analysis addressed in the present communication is that there may be substantial differences between members of the same patent family regarding the non-patent literature (NPL) references they may contain. This is especially the case for the examiner-incorporated references since the patents of a family tend to pass different examination processes in the different patent offices. The process may be slower or faster, and may lead to more or fewer NPL references being incorporated.

The process of registering a patent to protect an invention is neither easy nor cheap. A second problem addressed in this communication is that the protection of an invention in a technologically advanced country will give it a greater competitive edge and a greater potential market than in a developing country. Seeking protection in advanced countries with larger markets is harder and more expensive than it is in developing countries with small markets because greater benefits are expected from the invention. Therefore, a triadic patent - i.e. a set of corresponding patents filed in the European Patent Office (EPO), the United States Patent and Trademark Office (USPTO), and the Japan Patent Office (JPO) for the same invention with the same applicant or inventor-tends to have more economic and technological significance than a patent family covering one or more developing countries/regions.

A third problem is that there appear to exist large differences in the number of citations to scientific papers among patents and patent families. In a citation analysis of the scientific literature, advanced citation impact indicators correct for differences in the length of reference lists in scientific papers in a subject field. A similar "citing or source" normalization would be needed in an analysis of patent citations to take different patent families' propensity to cite scientific literature into account.

The aim of this study was to explore new indicators of the technological impact of recent research papers - indicators based on citations to the scientific literature that are found in patents, and taking into account the three problems outlined above:

1. To avoid differences in references to the scientific literature among patents from the same patent family, the patent family rather than an individual patent is taken as the basic unit on the "citing side" of the citation analysis. The SCImago Research Group has retrospectively assigned all non-patent references in the various members of a patent family to each patent in that family.

2. To differentiate among patent families according to the country/region in which patent protection was sought, a weight is assigned to each country/ region based on that country/region's state of economic development. A citation from a triadic patent then has greater weight than a patent citation from an economically developing country/region. In a country/region with greater economic and technological activity, it is more difficult and expensive 
to obtain a patent. When an applicant selects a country/region of this type it is because the patent involves state-of-the-art technology and is expected to yield significant economic benefits that will compensate for the investment.

3. The reciprocal of the number of references to scientific papers in a patent family is used as a weighting factor normalizing the number of patent family citations received by a scientific paper, thus correcting for differences among patent families in their propensity to cite the scientific literature. In this way, each patent family distributes its recognition (which is already weighted by the state of economic development of the countries/regions in which its patents are applying for protection) equitably among all of its references to scientific papers.

The newly proposed indicators of technological impact are applicable to the scientific production of countries, institutions, research groups, or even individual authors.

\section{Data}

Elsevier created and maintains Scopus, a bibliographic database of scientific literature (Hane, 2004; Pickering, 2004). It indexes more than 31,000 scientific journals, conference proceedings, and books. Several works have described its characteristics (Archambault et al., 2009; Leydesdorff, Moya Anegón, \& GuerreroBote, 2010; Moya-Anegón et al., 2007), and it has been used in numerous scientometric studies (Gorraiz, Gumpenberger, \& Wieland, 2011; Guerrero-Bote \& Moya-Anegón, 2015; Jacsó, 2011; Moya-Anegón et al., 2018). Scopus classifies publications by Subject Area, and then by Specific Subject Area or Category. There are more than 300 categories grouped under 26 subject areas. In addition, there is a Multidisciplinary Area that contains such journals as Nature or Science. The present study covers documents indexed in Scopus up to 2018 and published after 2002.

In 2008, at the behest of the patent statistics working group led by the Organization for Economic Co-operation and Development (OECD), the EPO released PATSTAT ("EPO Worldwide PATent STATistical Database"), designed to assist in statistical research on patents. There are other patent databases, such as NBER (the United States) and IIP (Japan). But PATSTAT has worldwide coverage, includes more information, and has some auxiliary products that can resolve various problems. For these reasons, PATSTAT has become a de facto standard (Kang \& Tarasconi, 2016). Nevertheless, it has two biases. One is towards European data since national patent offices exchange information with the EPO based on formal agreements (although these agreements change over time and leave some gaps). The other is towards the

Journal of Data and Information Science

http://www.jdis.org https://www.degruyter:com/view/j/jdis 


\section{Research Paper}

patent examination process since data that are not actually required in this process may be of lower quality. For the present study, we used the 2019 Spring edition.

PATSTAT collects references both to NPL and to patents. Due to its patent application and examination orientation, its data require debugging and standardizing to allow linkage with data taken from other databases. For example, the lack of standardization has long been a cause of problems in relating applicants and inventors with the data available in company databases. The first attempts to normalize names were made with the standardization tables of Thomson Scientific's Derwent World Patent Index (2007) and the USPTO's CONAME file, and further development and improvements are continuing to be made (Coffano \& Tarasconi, 2014; Lissoni, 2012; Lotti \& Marin, 2013; Magerman, Van Looy, \& Song, 2006; Maraut \& Martínez, 2014; Raffo \& Lhuillery, 2009; Thoma \& Torrisi, 2007; Schoen, Heinisch, \& Buenstorf, 2014).

In order to link the NPL citations in patents with scientific publications, one faces the same problem as in the case of the names of the applicants or inventorsnamely, the absence of standardization. We only know of one publicly available publication that has taken on this issue. It was part of the development of Lens Influence Mapping (Jefferson et al., 2018), and used PubMed and Crossref as the scientific literature databases. However, this study indicated neither how the cases in which a patent citation could be linked to more than one DOI (Digital Object Identifier) were resolved, nor how the method ensured that the retrieved documents actually corresponded to the patent-cited references they were linked with.

The SCImago Research Group has developed a procedure for linking the NPL references of the patents indexed in the PATSTAT database to the scientific papers indexed in the Scopus bibliographic database. This procedure has been implemented with reasonable results and assumable costs (Guerrero-Bote, Sánchez-Jiménez, \& Moya-Anegón, 2019; Moya-Anegón et al., 2020). It can be summarized as follows:

1. Data pre-processing: Preparation of the data to facilitate and streamline the subsequent processes.

2. Pre-selection of candidate pairs: Some coincidences of the elements of NPL references in PATSTAT and publication records in Scopus are used to preselect candidates for a matching pair.

3. Automated evaluation of candidate pairs: The matching elements of each candidate pair are evaluated, and the pair is assigned a score. Thus, for each NPL reference, an ordered list is obtained of the Scopus references that could match it.

Journal of Data and Information Science

4. Human validation: For each NPL reference, the top-ranked Scopus reference is checked manually, ensuring that they really do match. 
Since human validation plays a key role in the matching process, the precision was clearly going to be very high, but it still cannot be claimed to be $100 \%$. In the spring 2019 version of PATSTAT (the one used for this study), patent applications from 2003 or later include 54 million NPL references, of which 20 million are to documents dated 2003 or later, and, of these, 7.4 million have been linked following the above procedure. Few of the remaining 12.6 million references are scientific papers included in Scopus: from a manual check of a sample stratified by year of 600 of these remaining references, we estimated that only 0.37 million of them are actually documents included in Scopus, which would represent a recall of about $95 \%$.

\section{Methods}

In general terms, a patent family can be said to be a group of related patents. But there are different specific definitions of the concept (Martínez, 2011). The EPO (European Patent Office, 2019), for instance, uses two definitions:

- Simple family, DOCDB family, or Espacenet patent family: All applications of the family have the same priorities.

- Extended family or INPADOC family: All applications of the family are linked to the same root priority application. There may be applications in the same family that have no priority in common, but do have one in common with a third application which is the one that unites them.

In the present work, for convenience our focus is on the concept of a Simple family, which groups together all the applications corresponding to the same invention (European Patent Office, 2019).

As our goal was to develop indicators of the technological impact of recent scientific literature, we decided to take all patent applications into account, regardless of whether or not they had been granted. The reason was that if an applicant had taken the necessary steps to start the procedure then it was because the inventor and/ or applicant considered the invention to be commercially exploitable, regardless of whether for legal (e.g. the application was late) or other reasons the patent would ultimately be granted. It should also be noted that many patents are not exploited at all or are exploited only very briefly, which makes it hard to determine their value.

Just as not all scientific papers are equally important, not all patent applications have the same weight. Although there have been many studies on indicators of patent value, such as those relating to patent citations or renewals, these indicators require time to manifest themselves, i.e. time to be cited or time to be renewed. On top of this, there is the time necessary for a patent application to be published. This

Journal of Data and Information Science

http://www.jdis.org https://www.degruyter:com/view/j/jdis 


\section{Research Paper}

is why we elected to weight patent applications according to the countries/regions in which protection was being sought.

In order to differentiate among patent families according to this criterion, we decided to assign a weight to each country/region. We explored three candidate indicators with which to generate this weight: the number of patent applications in the country/region, the country/region's GDP, and its investment in R\&D. The first (the number of patent applications in a country/region) was discarded because of the existence of very small countries/regions with a small market but a disproportionate number of patents requesting protection, this being a consequence of regional offices and treaties such as the Eurasian Patent Organization (EAPO), the European Patent Office (EPO), and the European Patent Convention (EPC). The third (investment in R\&D) was ruled out due to the difficulty of getting reliable annual data and because there is no direct relationship between the amount of R\&D investment and patent applications. We therefore chose as the best option a weighting factor based on a country/region's GDP as an indicator of the commercial potential that was to be expected for that country/region. Specifically, a weight was defined for each country/region and for each particular year that was equal to its share of World GDP. The weight associated with a patent application is then determined by the country/region in which protection is requested in the filing year.

To weight citations from a patent family, an alternative approach would have been to use the absolute number of patents in the family or the number of designated countries/regions as the weighting factor. But such an approach would not take into account the state of economic development of the designated countries/regions. These criteria were therefore not used in the definition of the indicators that we finally explored.

While the NPL references may have different origins (applicant, examiner, opponent, etc.), no such differentiation was made in the present work. As will be outlined further below, both the number and the origin of NPL references are influenced by each national office's evaluation procedure, and this varies significantly from one country/region to another. Since patent families constitute the source or citing side of the citation process, duplicate references to scientific papers within each patent family's applications were merged into one. Also, to allow for differences among patents in the number of references to scientific papers, the aforementioned country/region weighting factor was divided by the total number of papers cited in each patent family.

For instance, for a patent family which makes $r$ citations to scientific papers, and which designates countries/regions $c_{1}$ and $c_{2}$ which have shares of World GDP equal to GDP. $c_{1}$ and GDP. $c_{2}$, respectively, the weighting factors $w_{1}$ and $w_{2}$ for those countries/regions $c_{1}$ and $c_{2}$ are calculated as follows: 


$$
w_{1}=\frac{G D P \cdot c_{1}}{r} ; w_{2}=\frac{G D P \cdot c_{2}}{r} .
$$

In the tables below, a weighting factor based solely on a country/region's share of World GDP will be denoted as a GDP-related weight, and a weighting factor resulting from dividing this share by the total number of a patent family's unique citations to papers as a fractional GDP-related weight.

In Table 1, patent families constitute the source or citing side of the citation process, and their citations to scientific papers are referred to as cites in the column headings. Articles published in the scientific literature constitute the target or cited side of the process, and are referred to as papers in the column headings. The countries/regions in the 1 st column are the 28 designated nations of the patent applications with the greatest weighted number of citations to scientific papers (see the last column). These 28 countries/regions together account for $98 \%$ of the total weighted number of citations to scientific papers.

One observes in Table 1 that 5,400,857 patent families have the United States as a designated country, although of course they may designate other countries/regions as well. These families contain 3,533,076 citations to scientific papers indexed in Scopus, so that the average number of citations to papers per patent family is 0.65 . Only a small percentage of patent families contain citations to papers, so that when only these families (those with at least one citation to papers) are considered then the average number of citations to papers per patent family rises to 33.29.

As mentioned above, for each patent family designating a given country/region, a weighting factor is calculated which is defined as the ratio between the designated country/region's share of World GDP and the patent family's total number of citations to papers. For example, calculating this ratio for all families designating the United States and having at least one citation to papers for each year considered, and computing the average over those years, one obtains a value of 0.234 . This number can be interpreted as the "value" of a citation in a patent family designating the United States to an arbitrary scientific paper. It therefore relates to the citing side of the citation process, not to the cited side. It will be used below as a type of source normalization factor in calculating a scientific paper's technological impact.

The "percentage weighted cites to papers" in the last column of Table 1 is calculated in the following manner. First, for each designation country/region the weighted number of citations to papers is calculated by multiplying the number of citations in patent families designating that country/region by its normalization factor. Next, these weighted numbers of citations are summed over all designation countries/regions. Finally, for each country/region, the share of weighted citations is computed relative to the sum over all countries/regions, expressed as a percentage.

Although it is unsurprising that the United States is the country with the largest share of weighted citations, it has fewer patent families than China and only slightly

Journal of Data and Information Science

http://www.jdis.org https://www.degruyter.com/view/j/jdis 


\section{Research Paper}

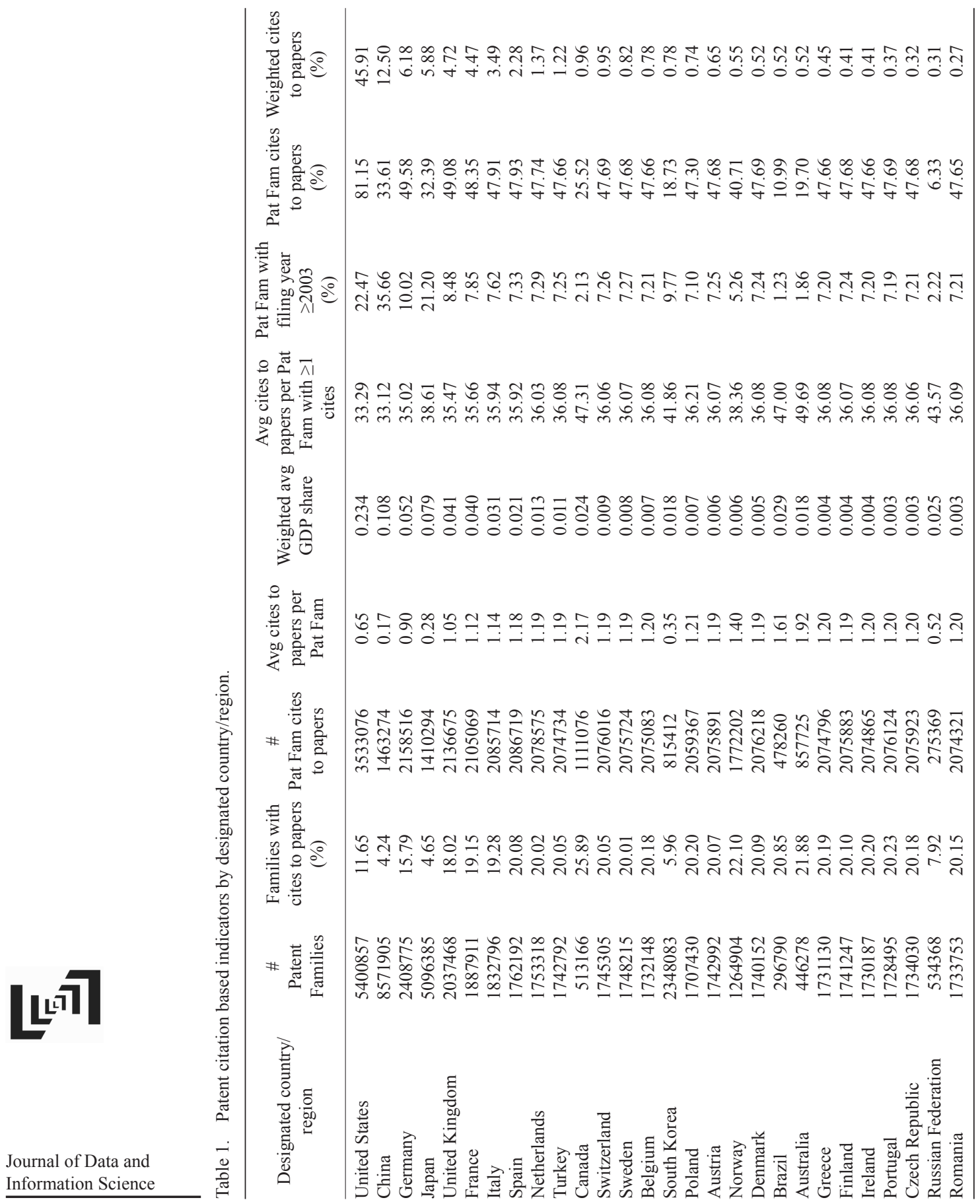




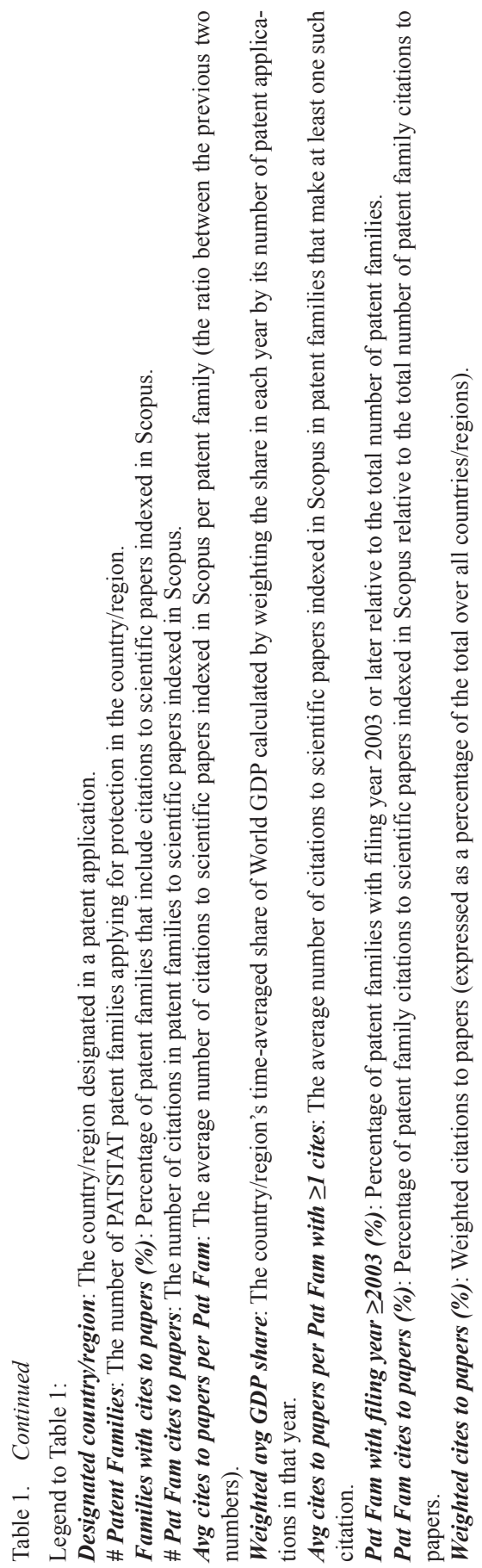




\section{Research Paper}

more than Japan. The main difference stems from the absolute number of patent citations to scientific papers, as can be seen in the 4th column. Specifically, in China and in Japan there must be many patents that do not cite any scientific paper indexed in Scopus.

In the 8th and 9th columns, one can clearly see the differences between a country/ region's percentage of patent families and its percentage of patent family citations. Keep in mind that there are many patent families that apply for protection in multiple countries/regions, which explains why these percentages sum to more than $100 \%$.

One also observes that there are differences between countries/regions in the average number of patent citations to papers. These reflect the differences among the patent authorities regarding their requirements and review processes. It can be seen that while the United States accounts for almost $45 \%$ of the weighted cites to papers, only three other countries/regions exceed $5 \%$.

Table 2. Patent citation according to document type of the cited paper.

\begin{tabular}{lccccc}
\hline \multicolumn{1}{c}{ Document type } & $\begin{array}{c}\text { \# Patent } \\
\text { families }\end{array}$ & $\begin{array}{c}\text { Avg cites to } \\
\text { papers }\end{array}$ & $\begin{array}{c}\text { Avg refs in } \\
\text { patents }\end{array}$ & $\begin{array}{c}\text { Avg cites to papers } \\
\text { (GDP-based } \\
\text { weighting) }\end{array}$ & $\begin{array}{c}\text { Avg cites to papers } \\
\text { (fractional GDP-based } \\
\text { weighting) }\end{array}$ \\
\hline Article & 670831 & 0.008 & 38.9 & 0.020 & 0.0023 \\
Conference Paper & 340577 & 0.018 & 17.4 & 0.025 & 0.0048 \\
Review & 177172 & 0.012 & 47.1 & 0.018 & 0.0019 \\
Short Survey & 24580 & 0.020 & 48.1 & 0.018 & 0.0013 \\
\hline
\end{tabular}

Legend to Table 2:

\# Patent families: Number of citing patent families.

Avg cites to papers: Average number of patent families citing any given document of that type.

Avg refs in patents: Average number of citations to papers in patent families which cite that document type.

Avg cites to papers (GDP-based weighting): Average number of citations weighted by a factor defined as a country/region's share of global GDP.

Avg cites to papers (fractional GDP-based weighting): Average number of citations weighted by a factor defined as a country/region's share of global GDP divided by the total number of a patent family's unique citations to papers.

Table 2 presents the data listed by the four "citable" document types: Article, Conference Paper, Review, and Short Survey. It shows that the most cited document type is Article followed by Conference Paper. However, although the Article is the most frequently occurring document type, if one considers the average number of citing patent families per paper (3rd column), the Short Survey ranks first, followed by the Conference Paper, the Review, and the Article. The 4th column lists the average number of citations to scientific papers indexed in Scopus that are included in patents that cite a particular document type. The Conference Paper receives on average less than half the number of citations received by the other types. The 5 th column gives the average number of citations weighted with the share of global

Journal of Data and Information Science GDP of designated countries/regions in patent families that cite a particular type of document, and the 6th column the average number of citations weighted with the 
fractional weight, as described above, defined as the ratio between a country/ region's share of global GDP and the total number of citations to papers in a citing patent family.

It is striking that Conference Papers have the greatest average fractional weight. This can be explained by the fact that in fields like computer science conference papers have greater relevance in combination with the observation (obtained from a secondary analysis not presented in the present communication) that the United States is the country with the greatest percentage of citations to conference papers as well as the greatest GDP-related weight of its patent families.

Table 3 is similar to Table 2, but relates to the cited papers' publication year rather than document type. It shows declines in the number of patent families, the average number of citations weighted with both the GDP share and the fractional weight. The more recent the paper, the less time it has had to be cited, as is true also for scientific paper-to-paper citations. The average number of citations to papers in the citing patents grew until 2013. This was to be expected since old patents have a smaller time frame from which to pick papers to cite (only post-2003 papers were considered) than that of more recently published patents.

Table 3. Patent citation according to publication year of the cited paper.

\begin{tabular}{rrrccc}
\hline Year & $\begin{array}{c}\text { \# Patent } \\
\text { families }\end{array}$ & $\begin{array}{c}\text { Avg cites to } \\
\text { papers }\end{array}$ & $\begin{array}{c}\text { Avg refs in } \\
\text { patents }\end{array}$ & $\begin{array}{c}\text { Avg cites to papers } \\
\text { (GDP-based } \\
\text { weighting) }\end{array}$ & $\begin{array}{c}\text { Avg cites to papers } \\
\text { (fractional GDP-based } \\
\text { weighting) }\end{array}$ \\
\hline 2003 & 230308 & 0.019 & 31.49 & 0.0218 & 0.00400 \\
2004 & 232905 & 0.019 & 33.77 & 0.0212 & 0.00350 \\
2005 & 229644 & 0.019 & 35.01 & 0.0208 & 0.00318 \\
2006 & 214822 & 0.019 & 35.43 & 0.0203 & 0.00292 \\
2007 & 205747 & 0.019 & 37.53 & 0.0202 & 0.00278 \\
2008 & 192682 & 0.019 & 39.03 & 0.0201 & 0.00261 \\
2009 & 177198 & 0.019 & 39.74 & 0.0195 & 0.00255 \\
2010 & 160483 & 0.019 & 40.16 & 0.0193 & 0.00249 \\
2011 & 140461 & 0.019 & 41.07 & 0.0191 & 0.00244 \\
2012 & 116753 & 0.018 & 42.90 & 0.0189 & 0.00233 \\
2013 & 87978 & 0.016 & 46.07 & 0.0188 & 0.00207 \\
2014 & 61586 & 0.014 & 42.73 & 0.0186 & 0.00178 \\
2015 & 38225 & 0.011 & 39.68 & 0.0185 & 0.00134 \\
2016 & 18082 & 0.006 & 42.64 & 0.0189 & 0.00064 \\
2017 & 6046 & 0.002 & 42.45 & 0.0202 & 0.00022 \\
2018 & 806 & 0.000 & 38.90 & 0.0191 & 0.00003 \\
\hline
\end{tabular}

Legend to Table 3:

\# Patent families: Number of citing patent families.

Avg cites to papers: Average number of patent families citing a document type.

Avg refs in patents: Average number of citations to papers in patent families citing a document type.

Avg cites to papers (GDP-based weighting): Average number of citations weighted by a factor defined as a country/region's share of global GDP.

Avg cites to papers (fractional GDP-based weighting): Average number of citations weighted by a factor defined as a country/region's share of global GDP divided by the total number of a patent family's unique citations to papers.

Journal of Data and Information Science http://www.jdis.org https://www.degruyter.com/view/j/jdis 


\section{Research Paper}

Table 4 is similar to Table 3, but gives results by Scientific Area. As expected, there are large differences between areas.

Table 4. Patent citation according to Scientific Area of the cited paper.

\begin{tabular}{|c|c|c|c|c|c|}
\hline Scientific Area & $\begin{array}{l}\text { \# Patent } \\
\text { families }\end{array}$ & $\begin{array}{l}\text { Avg cites } \\
\text { to papers }\end{array}$ & $\begin{array}{l}\text { Avg refs } \\
\text { in patents }\end{array}$ & $\begin{array}{c}\text { Avg cites to } \\
\text { papers } \\
\text { (GDP-based } \\
\text { weighting) }\end{array}$ & $\begin{array}{c}\text { Avg cites to } \\
\text { papers } \\
\text { (fractional } \\
\text { GDP-based } \\
\text { weighting) }\end{array}$ \\
\hline Computer Science & 251649 & 0.019 & 16.10 & 0.025 & 0.00525 \\
\hline Engineering & 394749 & 0.018 & 21.55 & 0.024 & 0.00466 \\
\hline Materials Science & 228670 & 0.018 & 23.88 & 0.024 & 0.00428 \\
\hline Physics and Astronomy & 204802 & 0.017 & 24.03 & 0.025 & 0.00401 \\
\hline Energy & 56034 & 0.020 & 15.61 & 0.022 & 0.00395 \\
\hline Mathematics & 111652 & 0.021 & 18.10 & 0.024 & 0.00386 \\
\hline Chemistry & 241128 & 0.015 & 27.28 & 0.020 & 0.00350 \\
\hline Chemical Engineering & 154459 & 0.017 & 33.27 & 0.020 & 0.00309 \\
\hline Decision Sciences & 11859 & 0.021 & 13.79 & 0.028 & 0.00280 \\
\hline Health Professions & 21004 & 0.017 & 29.71 & 0.021 & 0.00247 \\
\hline Environmental Science & 51047 & 0.015 & 24.88 & 0.020 & 0.00230 \\
\hline Pharmacology, Toxicology and Pharmaceutics & 120068 & 0.011 & 40.29 & 0.018 & 0.00227 \\
\hline Agricultural and Biological Sciences & 78973 & 0.012 & 34.36 & 0.018 & 0.00193 \\
\hline Dentistry & 4080 & 0.011 & 28.90 & 0.019 & 0.00192 \\
\hline Biochemistry, Genetics and Molecular Biology & 271492 & 0.007 & 45.62 & 0.018 & 0.00187 \\
\hline Earth and Planetary Sciences & 19357 & 0.009 & 15.67 & 0.022 & 0.00172 \\
\hline Medicine & 270703 & 0.006 & 46.07 & 0.018 & 0.00164 \\
\hline Multidisciplinary & 67184 & 0.017 & 55.33 & 0.019 & 0.00161 \\
\hline Immunology and Microbiology & 94414 & 0.009 & 46.12 & 0.018 & 0.00160 \\
\hline Business, Management and Accounting & 10229 & 0.010 & 11.89 & 0.030 & 0.00154 \\
\hline Veterinary & 10619 & 0.012 & 32.96 & 0.018 & 0.00153 \\
\hline Neuroscience & 43846 & 0.011 & 55.51 & 0.019 & 0.00141 \\
\hline Nursing & 13688 & 0.011 & 54.48 & 0.018 & 0.00132 \\
\hline Arts and Humanities & 37896 & 0.015 & 50.43 & 0.021 & 0.00128 \\
\hline Social Sciences & 22800 & 0.007 & 19.65 & 0.025 & 0.00100 \\
\hline Economics, Econometrics and Finance & 2044 & 0.004 & 11.76 & 0.034 & 0.00062 \\
\hline Psychology & 6026 & 0.006 & 63.15 & 0.021 & 0.00059 \\
\hline
\end{tabular}

Legend to Table 4:

\# Patent families: Number of citing patent families.

Avg cites to papers: Average number of patent families citing a document type.

Avg refs in patents: Average number of citations to papers in patent families citing a document type.

Avg cites to papers (GDP-based weighting): Average number of citations weighted by a factor defined as a country/region's share of global GDP.

Avg cites to papers (fractional GDP-based weighting): Average number of citations weighted by a factor defined as a country/region's share of global GDP divided by the total number of a patent family's unique citations to papers.

A general conclusion to be drawn from Tables 1-4 is that a large part of the scientific papers receive no citations from patents, and that patent citations are

Journal of Data and very unevenly distributed among the scientific areas, document types, and cited Information Science publication years. 


\section{Proposed indicator for countries/regions and other aggregates}

In developing a proposal for an indicator, we were inspired by the item-oriented, field-normalized, citation-score average indicator introduced by Lundberg (2007) which formed the base for the CWTS' mean normalized citation score (Waltman et al., 2011) and SCImago's normalized impact (SCImago Research Group, 2010). In this case however, we did not assume a priori that scientific contributions in all subject fields have the same technological value. It is clearly plausible that a contribution in Engineering or Pharmacology would have a greater technological impact than a contribution in the Humanities. We therefore decided not to implement any subject field normalization. Similar reasoning led us to also reject normalization according to document type.

Hence, we defined the Technological Impact of an aggregate as

$$
\mathrm{TI}=\frac{1}{n} \sum_{i=1}^{n} \frac{a_{i}}{e_{i}} ; a_{i}=\sum_{j=1}^{p} w_{i j}
$$

where $n$ is the number of (cited or not) papers published by the aggregate (e.g. an institution, a journal, a country/region), $a_{i}$ is the sum of the weights of the patent citations received by paper $i, e_{i}$ is the expected value of the sum of weights for papers of the same age, $p$ is the number of patent families citing the $i$-th paper ( $p$ depends on $i$ ), $w_{i j}$ is the weight of the citation from patent family $j$ received by the $i$-th paper as defined in Section 3:

$$
w_{i j}=\frac{G D P . c}{r}
$$

in which GDP represents the World GDP, $c$ a designated country/region's share of the World GDP, and $r$ the number of citations in a patent family to scientific papers indexed in Scopus. The indicator $T I$ is size-independent and, as a measure, corresponds to the average citation obtained by the aggregate's papers.

As an analogue of the total normalized citation score indicator known as "Brute Force", we define Technological Force as:

$$
\mathrm{TFO}=n \cdot \mathrm{TI}=\frac{\sum_{i=1}^{n} a_{i}}{e_{i}} .
$$

This indicator is size-dependent, and is a measure of the total technological contribution of the aggregate. 


\section{Research Paper}

\section{Results}

In analysing the behaviour of the indicators, only results for the main countries/ regions will be presented. We shall begin by focusing on TFO as a size-dependent indicator, and compare it with other size-dependent measures of a country/region's performance such as the number of patent families that have applied for protection in the country/region, its scientific publication output, a "brute force" indicator defined as the product of the publication output and the field-normalized citation impact, its scientific excellence output (Top 10\% and Top 1\%), and total citations from patent families to its scientific output. To make these size-dependent indicators more readily comparable, they will be expressed as percentages with respect to the global total. These percentages may sum to more than $100 \%$ because there are families that apply for protection in more than one country/region, and papers may be published in collaboration among several countries/regions.

Table 5 presents the scores of the 28 countries/regions with the highest value of TFO. In all indicators, the United States and China rank top, although not in the same proportions. In the 2nd column, which gives the percentage of families applying for protection in a country/region, one notes that China ranks higher than the United States. Also visible is the effect of the EPC. While in the past a designation fee was paid that depended on the designated countries/regions, since 2007 all European patent applications pay a single fee and designate all countries/regions. This causes many patents to seek protection in a large number of European Union countries, with the result being that around $7 \%$ of all patent families apply for protection in almost all countries of the EU.

One observes in the table that China has a smaller percentage of patent family citations than would have been expected given its total publication output. This is because patents that apply for protection in China are characterized by making few citations to papers, and those that cite papers from China itself even fewer. Nonetheless, these patents have an above-average weight precisely due to this low number of references and because China's GDP is the world's second largest, meaning that its cited references also contribute more, leading to a TFO within the expected range.

Figure 1 shows the same data as presented in Table 5 for the 12 countries/regions with the highest values of Technological Force (We plot just 12 countries/regions so that the profiles can be clearly seen.). The figure shows a large number of families applying for protection in China, Japan, and South Korea. Also, the EPC effect can be seen, with the other EU countries following in the wake of Germany and the United Kingdom in the number of patent families applying for protection. It is notable that India has a different profile, with relatively few patent families applying for protection in its territory. 
New Indicators of the Technological Impact of Scientific Production

Vicente P. Guerrero-Bote et al.

Research Paper

Table 5. Size-dependent indicators of the 28 top-ranked \%TFO countries/regions.

\begin{tabular}{lcrrrrrr}
\hline \multicolumn{1}{c}{ Country/Region } & \%Families & \%Output & \%BF & \%Exc10 & \%Exc1 & \%Fam.Cit. & \%TFO \\
\hline United States & 22.47 & 24.25 & 36.37 & 37.76 & 46.45 & 43.74 & 36.88 \\
China & 35.66 & 14.05 & 11.48 & 13.09 & 13.58 & 6.68 & 14.32 \\
Germany & 10.02 & 6.13 & 8.32 & 8.71 & 10.05 & 7.93 & 8.31 \\
Japan & 21.20 & 5.21 & 4.80 & 4.59 & 4.10 & 7.64 & 7.83 \\
United Kingdom & 8.48 & 7.05 & 10.85 & 11.23 & 14.03 & 7.19 & 6.50 \\
France & 7.85 & 4.30 & 5.57 & 5.86 & 6.56 & 4.59 & 4.74 \\
South Korea & 9.77 & 2.50 & 2.53 & 2.71 & 2.65 & 3.51 & 4.56 \\
Canada & 2.13 & 3.66 & 5.50 & 5.76 & 7.16 & 4.25 & 4.40 \\
Italy & 7.62 & 3.65 & 5.01 & 5.26 & 5.82 & 3.27 & 3.29 \\
India & 0.23 & 3.80 & 3.06 & 2.89 & 2.52 & 1.53 & 2.74 \\
Netherlands & 7.29 & 2.02 & 3.55 & 3.90 & 5.22 & 2.64 & 2.56 \\
Spain & 7.33 & 2.97 & 3.71 & 3.98 & 4.41 & 2.19 & 2.49 \\
Switzerland & 7.26 & 1.50 & 2.70 & 2.91 & 4.11 & 2.48 & 2.48 \\
Australia & 1.86 & 2.97 & 4.52 & 4.83 & 6.05 & 2.22 & 2.36 \\
Chinese Taiwan & 2.74 & 1.44 & 1.43 & 1.58 & 1.34 & 1.59 & 2.19 \\
Sweden & 7.27 & 1.33 & 2.16 & 2.31 & 2.93 & 1.70 & 1.65 \\
Belgium & 7.21 & 1.12 & 1.81 & 1.94 & 2.58 & 1.47 & 1.48 \\
Singapore & 0.31 & 0.66 & 1.11 & 1.25 & 1.79 & 0.97 & 1.33 \\
Denmark & 7.24 & 0.83 & 1.49 & 1.59 & 2.18 & 1.03 & 1.12 \\
Austria & 7.25 & 0.82 & 1.23 & 1.27 & 1.63 & 1.05 & 1.10 \\
Israel & 0.32 & 0.75 & 1.10 & 1.15 & 1.41 & 1.18 & 1.03 \\
Finland & 7.24 & 0.69 & 1.06 & 1.10 & 1.33 & 0.83 & 1.03 \\
Chinese Hong Kong & 0.30 & 0.69 & 1.13 & 1.31 & 1.71 & 0.79 & 1.00 \\
Brazil & 1.23 & 2.14 & 1.84 & 1.66 & 1.55 & 0.75 & 0.92 \\
Russian Federation & 2.22 & 2.12 & 1.36 & 1.06 & 1.04 & 0.60 & 0.78 \\
Poland & 7.10 & 1.41 & 1.23 & 1.07 & 1.15 & 0.59 & 0.76 \\
Norway & 5.26 & 0.67 & 1.08 & 1.08 & 1.37 & 0.51 & 0.72 \\
Iran & 0.00 & 1.28 & 1.16 & 1.28 & 1.17 & 0.33 & 0.65 \\
\hline
\end{tabular}

Legend to Table 5:

All the percentages are relative to the global total.

\%Families: Percentage of PATSTAT patent families with filing year 2003 or later applying for protection in the country/region.

\%Output: Percentage of scientific papers indexed in Scopus.

$\boldsymbol{\%} \boldsymbol{B F}$ : Brute Force percentage, i.e., \%Output $\times$ Normalized Impact (NI).

\%Exc10: Percentage of scientific papers of excellence (Top 10\%).

\%Exc1: Percentage of scientific papers of excellence (Top 1\%).

\%Fam.Cit.: Percentage of patent family citations received.

\%TFO: Percentage Technological Force.

Table 5 reveals Australia's low position in terms of the percentage of patent families citing its papers, and the EPC effect in Sweden and Belgium in this sense. Above all, one notes the high position of South Korea in the table (7th), while it ranks just 14th in terms of scientific output.

Table 6 gives the Pearson correlation coefficients between the size-dependent indicators of the 40 countries/regions with the greatest scientific outputs. The indicator that correlates least well with the others is Families, that corresponding to patent families applying for protection. There is a strong correlation between the indicators that combine quantity and quality of scientific production $(B F, E x c 10$,

Journal of Data and Information Science 


\section{Research Paper}

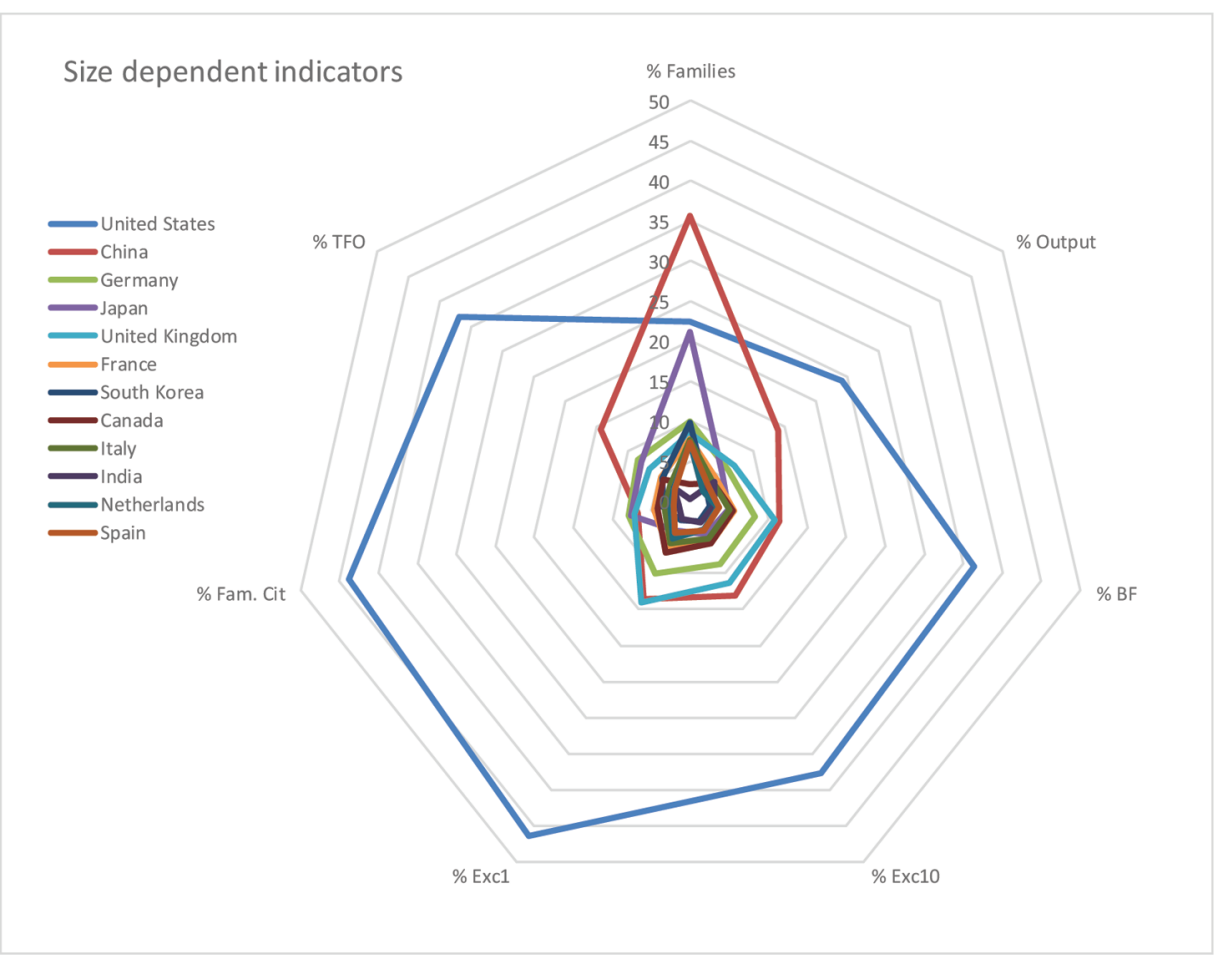

Figure 1. Size-dependent indicators of the 12 countries with greatest Technical Force.

Percentages relative to the global total.

\% Families: Percentage of PATSTAT patent families with filing year 2003 or later applying for protection in the country/region.

\% Output: Percentage of scientific papers indexed in Scopus.

$\% \boldsymbol{B F}$ : Brute Force percentage, i.e., \%Output $\times$ Normalized Impact (NI).

$\%$ Exc10: Percentage of scientific papers of excellence (Top 10\%).

\% Exc1: Percentage of scientific papers of excellence (Top 1\%).

\% Fam. Cit: Percentage of patent family citations received.

\% TFO: Percentage of Technological Force.

Table 6. Pearson correlation matrix between the size-dependent indicators for the 40 countries/regions with the greatest scientific output.

\begin{tabular}{lccccccc}
\hline & \%Families & \%Output & \%BF & \%Exc10 & \%Exc1 & \%Fam.Cit. & \%TFO \\
\hline \%Families & 1 & 0.72 & 0.60 & 0.61 & 0.58 & 0.55 & 0.68 \\
\%Output & 0.72 & 1 & 0.97 & 0.97 & 0.95 & 0.92 & 0.987 \\
\%BF & 0.60 & 0.97 & 1 & 0.99 & 0.99 & 0.98 & 0.98 \\
\%Exc10 & 0.61 & 0.97 & 0.99 & 1 & 0.99 & 0.97 & 0.98 \\
\%Exc1 & 0.58 & 0.95 & 0.99 & 0.99 & 1 & 0.97 & 0.97 \\
\%Fam.Cit. & 0.54 & 0.92 & 0.98 & 0.97 & 0.97 & 1 & 0.97 \\
\%TFO & 0.68 & 0.98 & 0.98 & 0.98 & 0.97 & 0.97 & 1 \\
\hline
\end{tabular}

Journal of Data and Information Science 
and Exc1). Technological Force has a stronger correlation with all the other indicators than the direct values of patent family citations.

The analyses presented in Tables 7 and 8 are analogous to those of Tables 5 and 6 , but based on size-independent rather than size-dependent indicators. The scores in these tables are relative to the global average, not the actual values of the indicators. The same set of 28 countries/regions are considered, i.e., those with the largest Technological Force (TFO), and they listed in Table 7 in the same order as in Table 5. But the actual ranking based on Technological Impact (TI) differs strongly from that based on TFO. Indeed, the top 10 countries/regions ranked by $T I$ would be Singapore (1.97), South Korea (1.67), Switzerland (1.62), United States (1.55), Finland (1.44), Chinese Hong Kong (1.41), Chinese Taiwan (1.40), Japan (1.40) Israel (1.35), and Denmark (1,33).

Table 7. Size-independent indicators of the 28 top-ranked \%TFO countries/regions.

\begin{tabular}{|c|c|c|c|c|c|c|c|}
\hline Country/Region & Fam.Rel. & $\% \mathrm{Q} 1$ & NI & $\%$ Exc10 & $\%$ Exc1 & Avg.Fam.Cit. & $\mathrm{TI}$ \\
\hline United States & 2.99 & 1.38 & 1.50 & 1.68 & 2.24 & 1.98 & 1.55 \\
\hline China & 2.97 & 0.83 & 0.82 & 1.00 & 1.13 & 0.46 & 0.92 \\
\hline Germany & 7.14 & 1.24 & 1.36 & 1.53 & 1.92 & 1.35 & 1.32 \\
\hline Japan & 5.23 & 1.09 & 0.92 & 0.95 & 0.92 & 1.47 & 1.40 \\
\hline United Kingdom & 6.00 & 1.37 & 1.54 & 1.72 & 2.33 & 1.17 & 0.98 \\
\hline France & 9.69 & 1.26 & 1.30 & 1.47 & 1.79 & 1.11 & 1.06 \\
\hline South Korea & 6.44 & 1.13 & 1.01 & 1.17 & 1.24 & 1.38 & 1.67 \\
\hline Canada & 4.17 & 1.39 & 1.50 & 1.69 & 2.29 & 1.25 & 1.20 \\
\hline Italy & 11.14 & 1.25 & 1.37 & 1.55 & 1.87 & 0.95 & 0.88 \\
\hline India & 0.18 & 0.70 & 0.81 & 0.82 & 0.78 & 0.41 & 0.69 \\
\hline Netherlands & 20.03 & 1.55 & 1.76 & 2.08 & 3.04 & 1.40 & 1.26 \\
\hline Spain & 13.70 & 1.24 & 1.25 & 1.44 & 1.74 & 0.77 & 0.81 \\
\hline Switzerland & 26.89 & 1.49 & 1.81 & 2.09 & 3.21 & 1.75 & 1.62 \\
\hline Australia & 3.78 & 1.38 & 1.52 & 1.75 & 2.39 & 0.81 & 0.80 \\
\hline Chinese Taiwan & 5.22 & 1.20 & 0.99 & 1.18 & 1.08 & 1.09 & 1.40 \\
\hline Sweden & 30.30 & 1.52 & 1.63 & 1.87 & 2.58 & 1.34 & 1.20 \\
\hline Belgium & 36.04 & 1.42 & 1.62 & 1.87 & 2.71 & 1.39 & 1.30 \\
\hline Singapore & 4.02 & 1.34 & 1.69 & 2.06 & 3.20 & 1.54 & 1.97 \\
\hline Denmark & 48.57 & 1.54 & 1.80 & 2.07 & 3.09 & 1.32 & 1.33 \\
\hline Austria & 48.83 & 1.27 & 1.50 & 1.66 & 2.32 & 1.35 & 1.30 \\
\hline Israel & 4.36 & 1.46 & 1.47 & 1.66 & 2.20 & 1.67 & 1.35 \\
\hline Finland & 58.69 & 1.38 & 1.54 & 1.73 & 2.27 & 1.25 & 1.44 \\
\hline Chinese Hong Kong & 3.53 & 1.39 & 1.64 & 2.06 & 2.92 & 1.20 & 1.41 \\
\hline Brazil & 3.33 & 0.88 & 0.86 & 0.84 & 0.85 & 0.36 & 0.40 \\
\hline Russian Fed. & 2.30 & 0.49 & 0.64 & 0.54 & 0.58 & 0.28 & 0.33 \\
\hline Poland & 28.16 & 0.79 & 0.87 & 0.82 & 0.95 & 0.42 & 0.50 \\
\hline Norway & 47.68 & 1.37 & 1.60 & 1.73 & 2.37 & 0.81 & 1.07 \\
\hline Iran & 0.00 & 0.74 & 0.91 & 1.08 & 1.07 & 0.25 & 0.47 \\
\hline
\end{tabular}

Legend to Table 7.

All indicators are relative to the global average, so that a value of unity would correspond to that global average. Fam.Rel.: Ratio between the number of patent families applying for protection in the country/region and its number of scientific papers. $\% \mathbf{Q 1}$ : Percentage of scientific papers in the first quartile.

NI: Normalized Impact.

\%Exc10: \% Excellence 10 (Top 10\%).

Journal of Data and

\%Exc1: \% Excellence 1 (Top 1\%).

Information Science

Avg.Fam.Cit.: Average number of patent family citations per paper.

TI: Technological Impact.

http://www.jdis.org https://www.degruyter.com/view/j/jdis 


\section{Research Paper}

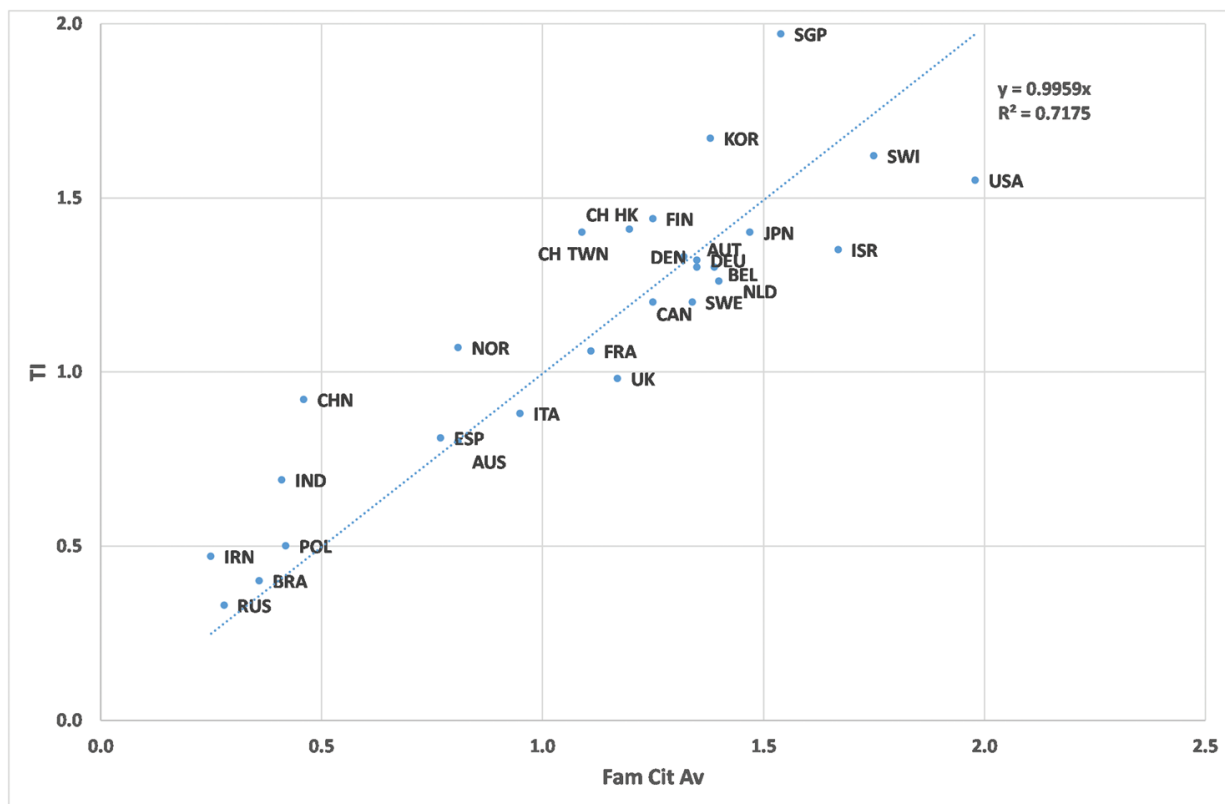

Figure 2. Technological Impact (TI) vs average number of patent family citations received per paper (Avg. Fam.Cit.) of the 28 countries/regions with the highest values of Technical Force.

Figure 2 is a scatter plot of Technological Impact (TI) vs the average number of patent family citations received (Avg.Fam.Cit.) for the 28 countries/regions with the greatest values of Technical Force $(T F O)$. While $T I$ is an advanced, normalized indicator, Avg.Fam.Cit. is a simpler, raw indicator. The plot clearly shows that Asian countries/regions in particular have relatively higher positions on the $T I$ scale than on the Avg.Fam.Cit. scale. This means that $T I$ indeed does make a difference in revealing features that remain hidden in analyses of straight patent citation counts.

Figure 3 is the size-independent analogue of Figure 1. The profiles it shows are more homogeneous than those shown in Figure 1 with there only being more variations in the average number of patent family citations.

The correlation matrix in Table 8 shows that Fam.Rel. (the ratio between a country/region's global share of patent families applying for protection and its global share of scientific papers) is the least correlated with the other indicators. The quality indicators of scientific production (\% Q1, NI, \% Exc10, and \% Exc1) have greater correlations with each other, and Technological Impact logically correlates more strongly with the average number of patent citations. Technological Impact correlates a little more strongly with \% Q1 and \% Exc10 than with the other two indicators of scientific quality. In any case, the correlations of TI are weaker (around Information Science 0.7) than those of TFO with the rest of the size-dependent indicators (around 0.9). 


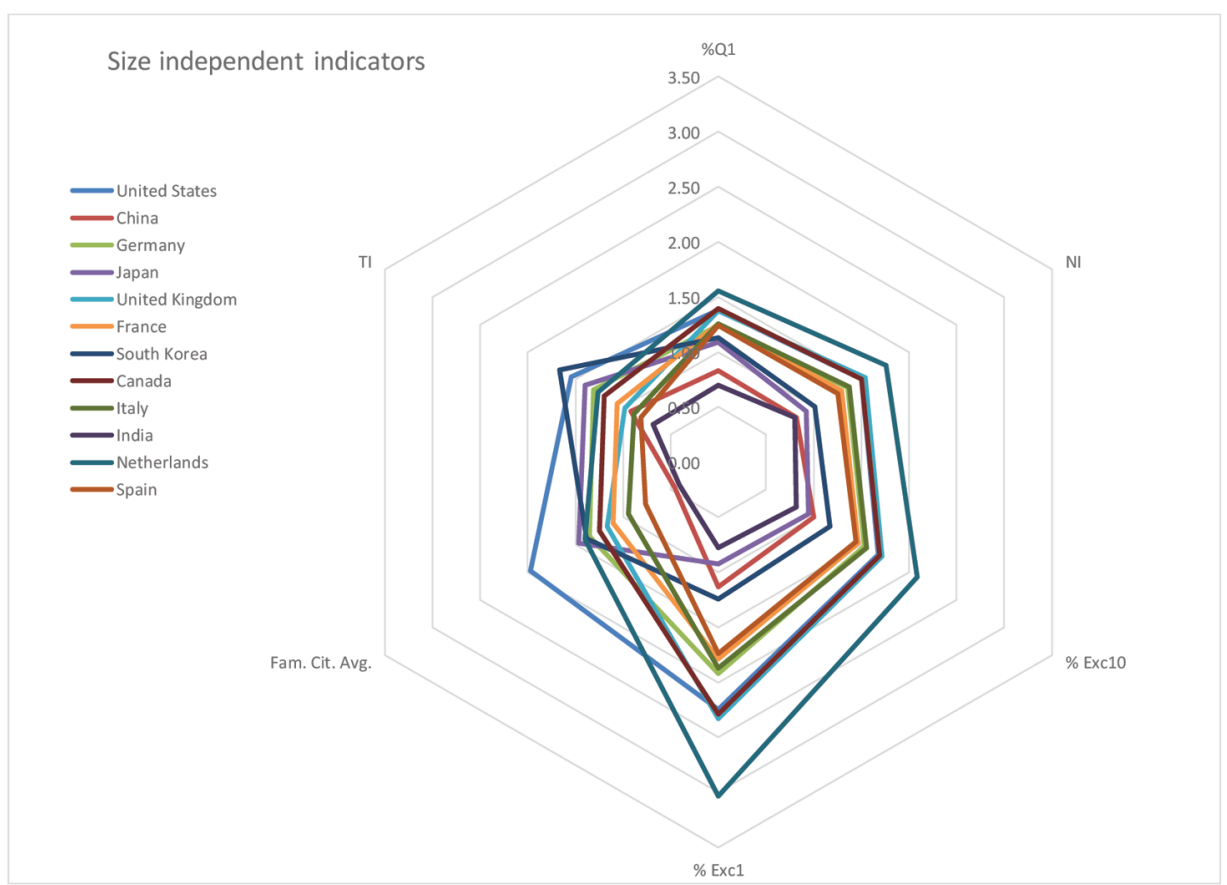

Figure 3. Size-independent indicators of the 12 countries with greatest Technical Force.

All indicators are relative to the global average.

\% Q1: Percentage of scientific papers in Q1.

NI: Normalized Impact.

\% Exc10: Percentage of scientific papers of excellence (Top 10\%).

\% Exc1: Percentage of scientific papers of excellence (Top 1\%).

Fam. Cit. Avg.: Average number of patent family citations per paper.

TI: Technological Impact.

Table 8. Pearson correlation matrix between size-independent indicators for the 40 countries/regions with the greatest scientific output.

\begin{tabular}{lccccccc}
\hline & Fam.Rel. & $\% \mathrm{Q} 1$ & NI & $\%$ Exc10 & \%Exc1 & Avg.Fam.Cit. & TI \\
\hline Fam.Rel. & 1 & 0.20 & 0.25 & 0.18 & 0.21 & 0.08 & -0.00 \\
\%Q1 & 0.20 & 1 & 0.92 & 0.92 & 0.86 & 0.83 & 0.74 \\
NI & 0.25 & 0.92 & 1 & 0.99 & 0.98 & 0.74 & 0.69 \\
\%Exc10 & 0.18 & 0.92 & 0.99 & 1 & 0.98 & 0.75 & 0.73 \\
\%Exc1 & 0.21 & 0.86 & 0.98 & 0.98 & 1 & 0.70 & 0.69 \\
Avg.Fam.Cit. & 0.08 & 0.83 & 0.74 & 0.75 & 0.70 & 1 & 0.90 \\
TI & -0.00 & 0.74 & 0.69 & 0.73 & 0.69 & 0.90 & 1 \\
\hline
\end{tabular}

Journal of Data and Information Science 


\section{Research Paper}

Figure 4 is a scatter plot of the countries/regions according to technological impact and scientific impact. One observes that Singapore has a high scientific impact, but above all stands out for its technological impact. Australia and the United Kingdom have significant scientific impact, but technological impact below the global average. Germany and Canada have lower scientific impact but greater technological impact. Japan, Chinese Taiwan, and South Korea stand out for their technological impact but not for their scientific impact.

The relative sizes of the circumferences also mark different profiles. While in Japan the thick circumference (Exc10) is the smallest, smaller than the two thin ones (TFO and patent family citations), in China the smallest is that of patent family citations. And in Australia and the United Kingdom, the largest circumference (TFO) is proportionally closer to the other two than in other countries/regions.

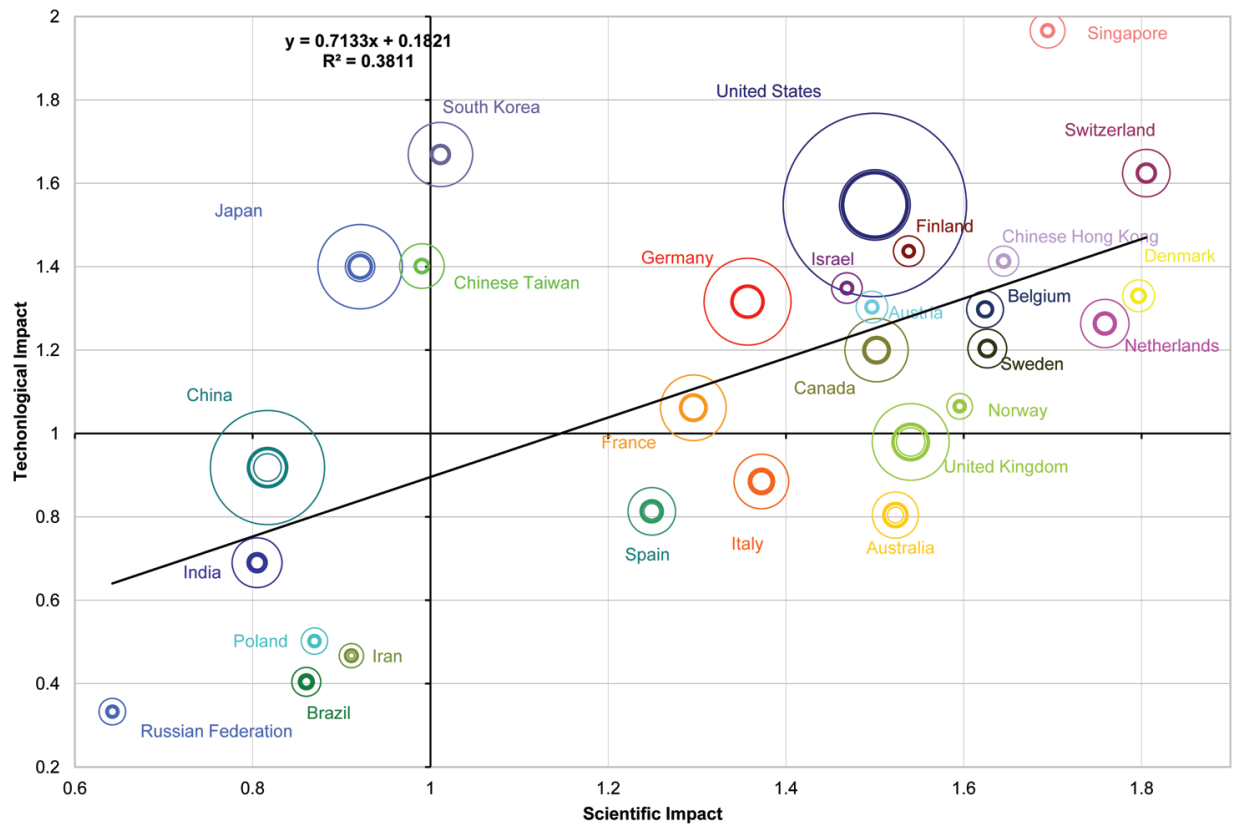

Figure 4. Scatter plot of Technological Impact vs Scientific Impact of the 28 countries/regions with the highest values of TFO. The circumferences correspond to: Technological Force (the outer thin circumference), Excellence 10 (thick circumference), the number of patent family citations (the inner thin circumference).

Figure 5 shows the temporal evolution of Technological Impact, Normalized Impact, and the average number of patent family citations for the two countries with the greatest scientific output and the countries/regions of the present authors. While the average citation rate from patent families has been in steady decline, TI has been

Journal of Data and Information Science stable except in the last two years. This loss of stability is due to the time it takes for the authorities to publish patent applications. 


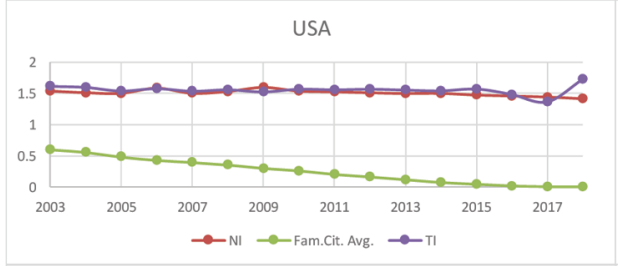

Netherlands

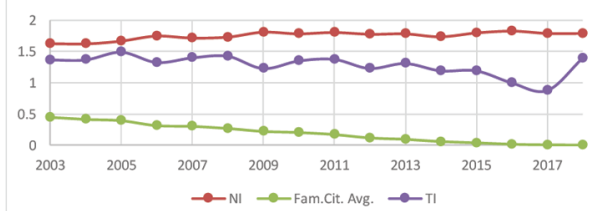

China

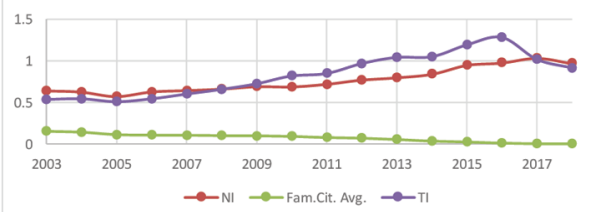

Spain

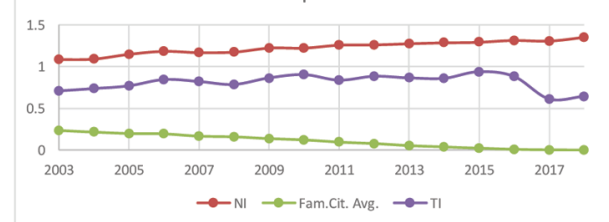

Figure 5. Annual evolution of three indicators - Normalized Impact (NI), average number of patent family citations (Fam.Cit. Avg.), and Technological Impact (TI) - in four countries.

\section{Conclusions}

The proposed indicators, Technological Impact (TI) and Technological Force $(T F O)$, are designed to complement each other-the first being size-independent, and the second size-dependent. Their construction takes into account the countries/ regions in which patent protection was sought, a patent family's propensity to cite scientific papers, merging and deduplication of the reference lists of applications corresponding to the same invention, and the time separating the publication date of a scientific paper and its subsequent citation in a patent.

Similar to the Normalized Scientific Impact indicator which normalizes the number of citations in scientific papers-to other papers with the average citation rate of articles in the same subject field and with the same publication year and document type, these advanced indicators of technological impact, being normalized with the scores corresponding to papers of the same age, are capable of partially eliminating the inevitable decline in patent citations to papers published in more recent years. It has to be noted, however, that the indicator $T I$ was found to lose stability in the last two years due to the time that it takes for the various authorities to publish patent applications.

The indicators explored in the present communication show strong linear correlations with the indicators of scientific production, but are also able to reveal features that remain hidden in analyses of straight patent citation counts. An example was seen in showing the uniqueness of such technologically advanced countries as Singapore, South Korea, or Japan whose R\&D systems are better integrated with innovation.

Journal of Data and Information Science

http://www.jdis.org https://www.degruyter.com/view/j/jdis 


\section{Research Paper}

The proposed indicators are useful tools with which to characterize the technological orientation of research institutions.

\section{Acknowledgments}

This work was financed by the Plan Estatal de Investigación Científica y Técnica y de Innovación 2013-2016 and the Fondo Europeo de Desarrollo Regional (FEDER) as part of research project CSO2016-75031-R.

\section{Author contributions}

Vicente P. Guerrero-Bote (guerrero@unex.es): Conceptualization (Equal), Data curation (Equal), Formal analysis (Equal), Funding acquisition (Lead), Investigation (Equal), Methodology (Lead), Project administration (Lead), Resources (Equal), Software (Lead), Supervision (Equal), Validation (Equal), Visualization (Equal), Writing-original draft (Lead), Writing-review \& editing (Equal); Henk F. Moed (henk.moed@uniroma1.it): Conceptualization (Equal), Data curation (Equal), Formal analysis (Equal), Funding acquisition (Equal), Investigation (Equal), Methodology (Equal), Project administration (Equal), Resources (Equal), Software (Equal), Supervision (Equal), Validation (Lead), Visualization (Equal), Writing-original draft (Equal), Writing-review \& editing (Lead); Félix Moya-Anegón (felix.moya@scimago.es): Conceptualization (Equal), Data curation (Supporting), Formal analysis (Supporting), Funding acquisition (Equal), Investigation (Equal), Methodology (Equal), Project administration (Equal), Resources (Equal), Software (Supporting), Supervision (Supporting), Validation (Supporting), Visualization (Supporting), Writing-original draft (Supporting), Writing-review \& editing (Supporting).

\section{References}

Ahmadpoor, M., \& Jones, B.F. (2017). The dual frontier: Patented inventions and prior scientific advance. Science, 357(6351), 583-587.

Archambault, E., Campbell, D., Gingras, Y., \& Larivière, V. (2009). "Comparing bibliometric statistics obtained from the Web of Science and Scopus". Journal of the American Society for Information Science and Technology, 60 (7), 1320-1326. https://doi.org/10.1002/asi.21062

Bryan, K.A., Ozcan, Y., \& Sampat, B. (2020). In-text patent citations: A user's guide. Research Policy, 49(4), 103946.

Callaert, J., Pellens, M., \& Van Looy, B. (2014). Sources of inspiration? Making sense of scientific references in patents. Scientometrics, 98(3), 1617-1629.

Coffano, M., \& Tarasconi, G. (2014). Crios-Patstat database: Sources, contents and access rules. Center for Research on Innovation, Organization and Strategy, Crios Working Paper n. 1. https://ssrn.com/abstract=2404344 (accessed: 01/06/2020). https://doi.org/10.2139/ssrn.2404344

Derwent. (2007). World Patents Index-Derwent patentee codes, Revised edition 8. Thomson Corporation. Leuven Manual. ISBN: 090115738 4. http://ips.clarivate.com/m/pdfs/mgr/ patenteecodes.pdf

Journal of Data and Information Science

European Patent Office. (2019). Data catalog Patstat global. Versión 5.13. EPO Patstat customers. https://www.epo.org 
Gorraiz, J., Gumpenberger, C., \& Wieland, M. (2011). "Galton 2011 revisited: A bibliometric journey in the footprints of a universal genius". Scientometrics, 88(2), 627-652. https://doi. org/10.1007/s11192-011-0393-y

Guerrero-Bote, V.P., \& Moya-Anegón, F. (2015). “Analysis of scientific production in food science from 2003 to 2013”. Journal of food science, 80(12), R2619-R2626. https://doi.org/10.1111/ 1750-3841.13108

Guerrero-Bote, V.P., Sánchez-Jiménez, R., \& Moya-Anegón, F. (2019). “The citation from patents to scientific output revisited: A new approach to Patstat / Scopus matching". El profesional de la información, 28(4), e280401. https://doi.org/10.3145/epi.2019.jul.01

Hane, P.J. (2004). "Elsevier announces Scopus service". Information today. http://newsbreaks. infotoday.com/nbreader.asp? ArticleID=16494 (accessed: 01/06/2020).

Hinze, S., \& Schmoch, U. (2004). Opening the black box. In: Moed, H.F., Glänzel, W., and Schmoch, U. (2004) (eds.). Handbook of quantitative science and technology research. The use of publication and patent statistics in studies of S\&T systems. Dordrecht (the Netherlands): Kluwer Academic Publishers, 215-235.

Jacsó, P. (2011). "The h-index, h-core citation rate and the bibliometric profile of the Scopus database". Online information review, 35(3), 492-501. https://doi.org/10.1108/1468452111 1151487

Jefferson, O.A., Jaffe, A., Ashton, D., Warren, B., Koellhofer, D., Dulleck, U., Bilder, G., Ballagh, A., Moe, J., DiCuccio, M., Ward, K., Bilder, G., Dolby, K., \& Jefferson, R.A. (2018). "Mapping the global influence of published research on industry and innovation". Nature biotechnology, 36(1), 31-39. https://doi.org/10.1038/nbt0818-772a

Kang, B., \& Tarasconi, G. (2016). "Patstat revisited: Suggestions for better usage". World patent information, 46, 56-63. https://doi.org/10.1016/j.wpi.2016.06.001

Leydesdorff, L., Moya Anegón, F., \& Guerrero-Bote, V.P. (2010). "Journal maps on the basis of Scopus data: A comparison with the Journal Citation Reports of the ISI". Journal of the American Society for Information Science and Technology, 61(2), 352-369. https://doi. org/10.1002/asi.21250

Lissoni, F. (2012). "Academic patenting in Europe: An overview of recent research and new perspectives". World patent information, 34(3), 197-205. https://doi.org/10.1016/j.wpi.2012. 03.002

Lotti, F., \& Marin, G. (2013). "Matching of Patstat applications to AIDA firms: Discussion of the methodology and results". Bank of Italy occasional paper, n. 166. https://ssrn.com/abstract= 2283111 (accessed: 01/06/2020). https://doi.org/10.2139/ssrn.2283111

Lundberg, J. (2007). "Lifting the crown — citation z-score". Journal of Informetrics, 1(2), 145-154. https://doi.org/10.1016/j.joi.2006.09.007

Magerman, T., Van-Looy, B., \& Song, X.Y. (2006). Data production methods for harmonized patent statistics: Patentee name standardization. Technical report, K.U. Leuven. https://ec.europa.eu/ eurostat/documents/3888793/5836029/KS-AV-06-002-EN.PDF (accessed: 01/06/2020).

Maraut, S., \& Martínez, C. (2014). "Identifying author-inventors from Spain: Methods and a first insight into results”. Scientometrics, 101(1), 445-476. https://doi.org/10.1007/s11192-0141409-1

Martínez, C. (2011). "Patent families: When do different definitions really matter?", Scientometrics, v. 86, pp. 39-63. https://doi.org/10.1007/s11192-010-0251-3

Journal of Data and Information Science

http://www.jdis.org https://www.degruyter.com/view/j/jdis 


\section{Research Paper}

Moya-Anegón, F., Chinchilla-Rodríguez, Z., Vargas-Quesada, B., Corera-Álvarez, E., MuñozFernández, F.J., González-Molina, A., \& Herrero-Solana, V. (2007). "Coverage analysis of Scopus: A journal metric approach". Scientometrics, 73(1), 53-78. https://doi.org/10.1007/ s11192-007-1681-4

Moya-Anegón, F., Guerrero-Bote, V.P., López-Illescas, C., \& Moed, H.F. (2018). "Statistical relationships between corresponding authorship, international co-authorship and citation impact of national research systems". Journal of informetrics, 12(4), 1251-1262. https://doi. org/10.1016/j.joi.2018.10.004

Moya-Anegón, F., López-Illescas, C., Guerrero-Bote, V.P., \& Moed, H.F. (2020). The citation impact of social sciences and humanities upon patentable technology. Scientometrics, to be published.

Narin, F., \& Olivastro, D. (1992). Status report: Linkage between technology and science. Research Policy, 21, 237-249.

Narin, F., Hamilton, K.S., \& Olivastro, D. (1997). The increasing linkage between US technology and public science. Research Policy, 26, 317-330.

Organisation for Economic Co-operation and Development. (2009). OECD Patent Statistics Manual, OECD, Paris. https://www.oecd.org/sti/inno/oecdpatentstatisticsmanual.htm

Pickering, B. (2004). "Elsevier prepares Scopus to rival ISI Web of science". Information world review, n. 8.

Poege, F., Harhoff, D., Gaessler, F., \& Baruffaldi, S. (2019). Science quality and the value of inventions. Science advances, 5(12), easy 7323.

Price, D.J.D (1965). Networks of scientific papers. Science, 149, 510-515.

Raffo, J.D., \& Lhuillery, S. (2009). "How to play the 'Names game': Patent retrieval comparing different heuristics". Research policy, 38(10), 1617-1627. https://doi.org/10.2139/ssrn. 1441172

Schmoch, U., \& Khan, M. (2019). Methodological challenges for creating patent indicators. In: Glanzel, W., Moed, H.F., Schmoch, U., \& Thelwall, M. (eds.), Springer Handbook of Science and Technology Indicators. Cham (Switzerland): Springer Nature, 907-927.

Schoen, A., Heinisch, D., \& Buenstorf, G. (2014). "Playing the 'Name game' to identify academic patents in Germany”. Scientometrics, 101(1), 527-545. https://doi.org/10.1007/s11192-014$1400-\mathrm{x}$

SCImago Research Group. (2010). SIR Methodology: General Considerations. https://www. scimagoir.com/methodology.php (accessed: 01/06/2020).

【ัเงฺ|

Thoma, G., \& Torrisi, S. (2007). Creating powerful indicators for innovation studies with approximate matching algorithms. A test based on Patstat and Amadeus databases (No. 211). KITeS, Centre for Knowledge, Internationalization and Technology Studies, Università Bocconi, Milano, Italy. http://citeseerx.ist.psu.edu/viewdoc/download?doi=10.1.1.573.8107 $\&$ rep=rep1\&type $=$ pdf (accessed: 01/06/2020).

Van Raan, A.F.J. (2017). Patent Citations Analysis and Its Value in Research Evaluation: A Review and a New Approach to Map Technology-relevant Research. Journal of Data and Information Science, 2, 13-50.

Journal of Data and Information Science

Veugelers, R., \& Wang, J. (2019). Scientific novelty and technological impact. Research Policy, 48(6), 1362-1372. 


\section{Research Paper}

Waltman, L., van Eck, N.J., van Leeuwen, T.N., Visser, M.S., \& van Raan, A.F. (2011). “Towards a new crown indicator: Some theoretical considerations". Journal of informetrics, 5(1), 37-47. https://doi.org/10.1016/j.joi.2010.08.001

\section{(c) $\oplus \odot \ominus$}

This is an open access article licensed under the Creative Commons Attribution-NonCommercialNoDerivs License (http://creativecommons.org/licenses/by-nc-nd/4.0/). 